\title{
Mammalian Homologs of Drosophila ELAV Localized to a Neuronal Subset Can Bind in vitro to the 3' UTR of mRNA Encoding the Id Transcriptional Repressor
}

\author{
Peter H. King, ${ }^{1}$ Todd D. Levine, ${ }^{1}$ Robert T. Fremeau, Jr., ${ }^{2}$ and Jack D. Keene ${ }^{1}$ \\ Departments of 'Microbiology and 2Pharmacology, Duke University Medical Center, Durham, North Carolina 27710
}

\begin{abstract}
Mammalian cDNAs encoding a rat (Rel-N1) and a human (Hel-N1) neuronal RNA-binding protein have been cloned and characterized with respect to tissue specificity, neuroanatomical localization, and RNA binding specificity. Both proteins are highly similar to the product of the Drosophila elav gene, which is expressed in all neurons of the fly and is required for development of the nervous system. However, in situ hybridization of rat tissues demonstrated more restricted expression of Rel-N1 mRNA within a subset of neurons of the hippocampus, cortex, and other regions of the gray matter, but not in glial cells or white matter. In vitro RNA binding experiments demonstrated that Hel-N1 can bind to the $3^{\prime}$ untranslated region ( $3^{\prime}$ UTR) of Id mRNA, a transcript that encodes a helix-loop-helix transcriptional repressor that is abundantly expressed in undifferentiated neural precursors. Sequences characterized for Hel-N1 binding were also abundantly present in the $3^{\prime}$ UTR of the Drosophila extramacrochaetae mRNA, which encodes an Id homolog. Thus, we have identified a potential link between a neuronal 3' UTR RNA-binding protein and regulatory transcription factors involved in neural development. These findings are interpreted in light of recent studies in which mRNA 3 UTRs were found to be important for the regulation of cell growth and differentiation.
\end{abstract}

Key words: $R$ NA-binding proteins, RNA recognition motif helix-loop-helix, inhibitor of DNA binding, paraneoplastic diseases, 3 untranslated region, differentiation, autoimmunity]

The Drosophila elav gene locus encodes a protein of vital importance in the carly development of the CNS (Campos et al., 1985; Jiminez and Campos-Ortega, 1987). Mutations of this gene locus give rise to a lethal phenotype with numerous structural defects and hypotrophy of the CNS. Its role in neuronal growth and differentiation of the Drosophila nervous system is also underscored by the appearance of elav transcripts following the differentiation of neuroblasts into primitive neurons (Robinow and White, 1988). Another Drosophila protein termed

Received June 16, 1993; revised Aug. 30, 1993; accepted Sept. 14, 1993

This work was supported by research grants from the National Institutes of Health to I.D.K. P.H.K. was supnorted by Nelrobehavioral Training Grant MH15177, and T.D.L. was supported by the Four Schools Physician-Scientist Program.

Correspondence should be addressed to Jack D. Keene, Box 3020,406 Jones Building. Duke University Medical Center, Durham. NC 27710

Present address: Department of Neurology, University of Alabama Medical Center, Birmingham. AL 35233.

Copyright 1994 Society for Neuroscience 0270-6474/94/141943-10\$05.00/0 rbp 9 is also similar to elav but mutants have not been charactcrized (Kim and Baker, 1993b).

The cDNA cloning of elav revealed that it possesses three potential RNA binding domains (Robinow et al., 1988) based upon the presence of three sets of two conserved core elements, the RNP 1 and RNP 2 consensus sequences (Adam et al., 1986; Dreyfuss et al., 1988). These elements are part of a common RNA recognition motif (termed $R R M$ ) that was shown to be encompassed within a functionally defined RNA-binding domain (Qucry ct al., 1989; reviewed in Kenan et al., 1991).

In the present study, we have used degenerate probes and PCR to isolate human and rat cDNA homologs of the Drosophila ELAV protein. The human counterpart is designated Hel-N1 for human elav-like neuronal protein 1 and the rat counterpart as Rel-N1 for rat elav-like neuronal protein 1 . We found that the mRNA of Rel-N1 is expressed only in neuronal tissue and in a subset of CNS neurons in the adult rat. It was not detected in glial cells or white matter and was found abundantly in portions of hippocampus, cerebral cortex, and brainstem. Sequence comparisons of Drosophila elav and $r b p 9$ with Hel-N1 and Rel-N 1 suggest the existence of a subfamily of elavlike genes. All of the ELAV-like proteins are highly homologous in their three RRMs, suggesting that they may have similar RNA-binding targets.

Here we demonstrate that $\mathrm{Hel}-\mathrm{N} 1$ binds in vitro to mRNA encoding a transcriptional repressor protein termed "inhibitor of DNA binding" or abbreviated Id (Benczra et al., 1990). Id has been implicated in muscle cell development of mice because of its interactions with the transcription factor MyoD (Benezra et al., 1990). Expression of Id and a human homolog, Id2, were recently reported to occur during early development of neural tissue (Duncan et al., 1992; Biggs et al., 1992). We report here that binding of Ifel-N1 to Id minNA was dependent upon the integrity of sequences in the 3 ' untranslated region (3'UTR) of the Id transcript. Interestingly, Id mRNA was found to contain short stretches of uridylate residues in the 3' UTR that resemble sequences present in growth factor mRNAs (Shaw and Kamen, 1986) that are known to interact with Hel-Nl (Levine et al., 1993). These data raise the possibility that Hel-N1 is involved in modulating the expression of transcriptional regulators of the helix-loop-helix family that are known to play a role in neural and muscle cell growth and differentiation.

\section{Materials and Methods}

Cloning Hel-NI by PCR. Degenerate polymerase chain reaction (PCR) primers were synthesized based on the first seven amino acids of the RNP1 consensus sequence in the firs1 RRM (Fig. 1. A amino acids 203- 




ELAV G E I E S S K K I I R D K S

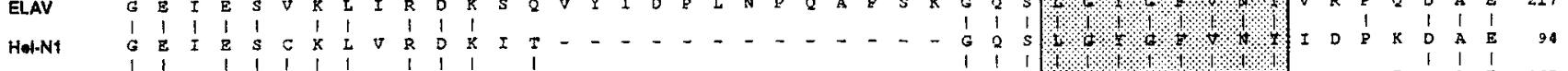

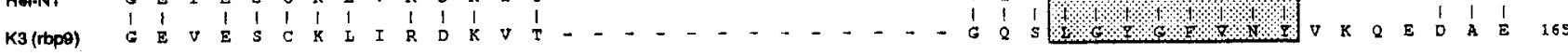

ELAV Q A V N V L N G I R L Q N K T I K V S F A R P S S D A I K G A

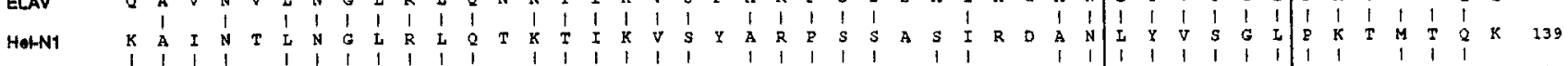



ELAV E L E E A I I F A P P F G G A I I T T S R I I L Q N

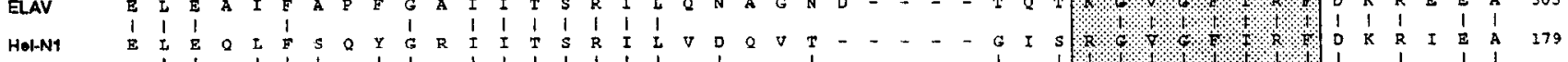

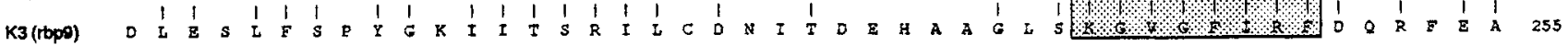

ELAV T $T$ A



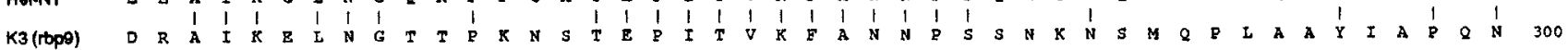

ELAV I V R R

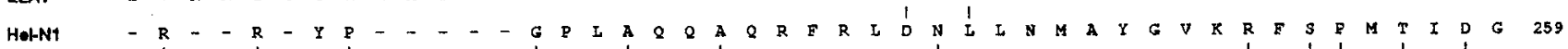

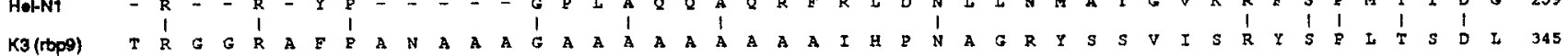

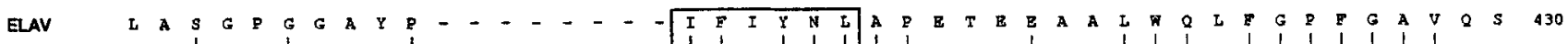

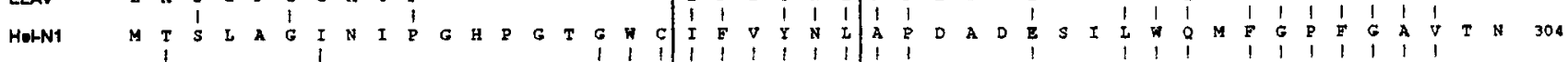

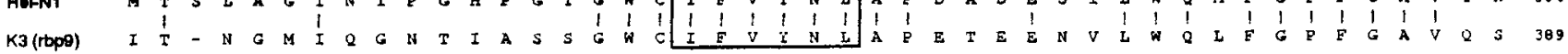

ELAV V K I V K D



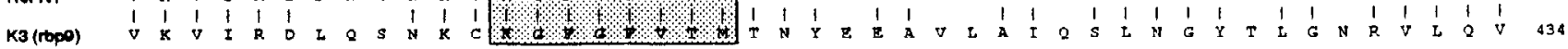

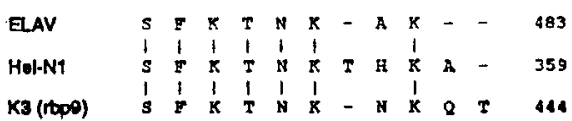

Figure 1. A, Amino acid and nucleotide sequence of Hel-N1 in comparison to Drosophila proteins ELAV and rbp9. Boxes represent the RNPI octamer sequence (shaded boxes) and the RNP2 hexamer sequence (unshaded boxes) of each of the three RNA recognition motifs. B, Comparison of the amino acid sequences in the RNA recognition motif of Hel-N1 with those in the Drosophila proteins ELAV and rbp9 according to the alignment of Kenan et al. (1991) and Hoffman et al. (1991). 


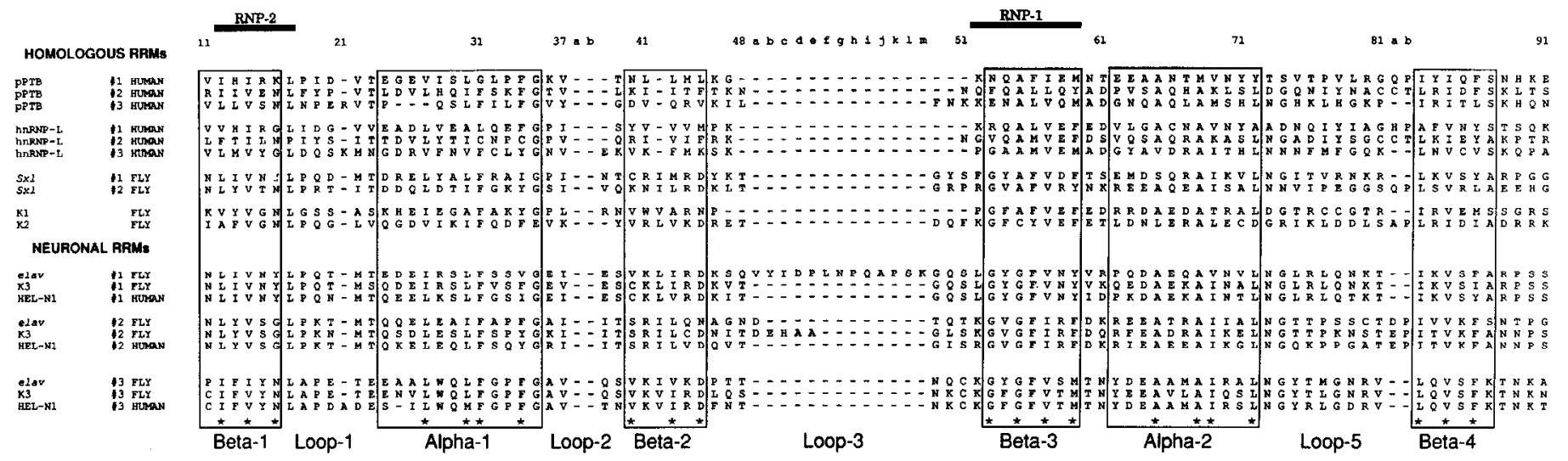

Figure 1. Contined.

210 ; in sense orientation) and second RRM (Fig. 1A, amino acids 290297; in antisense orientation) of elav. Inosine residues were placed in positions degenerate for all four nucleotides and EcoRI restriction sites were placed at the 5 ' end of each oligonucleotide. cDNA was prepared by reverse transcribing total cytoplasmic RNA from an adult SpragueDawley rat pup brain using $6 \mathrm{mg}$ of RNA, $1 \mathrm{~mm}$ dNTPs, 100 pmol of random hexamers (Pharmacia), GeneAmp buffer, $20 \mu \mathrm{g}$ of RNASIN (Promega), and 200 U of reverse transcriptase (Bethesda Research Labs). Forty cycles of PCR amplification were carried out using an annealing temperature of $37^{\circ} \mathrm{C}$ and an extension temperature of $55^{\circ} \mathrm{C}$ (cycles $1-$ 4) and $72^{\circ} \mathrm{C}$ (cycles $5-40$ ). A PCR product of 281 nucleotides was purified on a $1 \%$ agarose gel using Geneclean (Bio 101) and subcloned into a TA vector (In Vitrogen). The clone, Rel-N1, was sequenced and found to have a high degree of homology with elav, including a $100 \%$ homologous RNP2 consensus sequence within the second RRM.

Random-primed cDNA probes (Feinberg and Vogelstein, 1983) were generated from Rel-N1 using standard methods before screening a $\lambda$ ZAPII human fetal brain cDNA library (Stratagene). Seven positive plaques were isolated from an initial population of 500,000 phage screened using the following hybridization conditions: $50 \%$ formamide, $6 \times$ saline-sodium citrate (SSC), $0.1 \%$ SDS, and $0.01 \%$ BLOTTO. Filters were hybridized for $18 \mathrm{hr}$ at $42^{\circ} \mathrm{C}$ and washed two times at room temperature $(10 \mathrm{~min}$ each) in $2 \times \mathrm{SSC}, 0.1 \% \mathrm{SDS}$ followed by a final wash at $65^{\circ} \mathrm{C}$ in $0.2 \times \mathrm{SSC}, 0.1 \% \mathrm{SDS}$ for $45 \mathrm{~min}$. The Bluescript plasmids of the positive phage were then isolated according to the manufacturer's specifications (Stratagene).

Sequencing $\mathrm{Hel}-\mathrm{N1}$. EcoRI inserts within the Bluescript plasmids were sequenced by exonuclease digestion and primer extension using the dideoxynucleotide chain termination (Sanger et al., 1977) with a modified T7 DNA polymerase (Tabor and Richardson, 1987) from the Sequenase system (U.S. Biochemicals). Oligonucleotides were synthesized on an Applied Biosystems 391 DNA synthesizer.

Expression of Hel-N1 in Escherichia coli. An inducible T7 RNA polymerase expression system (Rosenberg et al., 1987) was used for production of Hel-N1 protein. By using PCR mutagenesis, a conservative point mutation was introduced into the carboxy portion of the open reading frame (ORF) to delete an NcoI site, such that the only Ncol site remaining was at the translation-initiation methionine. An $\mathrm{NcoI}-\mathrm{EcoRI}$ insert from this construct was subcloned in frame into $\mathrm{pET}$ $3 \mathrm{c}$ containing the T7 12-amino acid ( 10 ) sequence at the $5^{\prime}$ cloning site (Bentley and Keene, 1991; Tsai et al., 1992). After transfection of this construct into BL21(DE3)pLysS, the bacteria were induced with isopropyl thiogalactopyranoside. The cells were washed twice in SM buffer and then resuspended in a small volume of $E$. coli lysis buffer [ $1 \times$ Tris-buffered saline (TBS), $10 \mathrm{~mm}$ EDTA, 0.05\% Tween, $3 \mathrm{~mm}$ dithiothreitol (DTT), and phenylmethylsulfonyl fluoride (PMSF)]. Lysis was completed by freeze-thawing the cells. The extract was centrifuged at $10,000 \times g$ to remove insoluble debris. The amount of expressed protein was evaluated by SDS-polyacrylamide gel electrophoresis and Western blotting as well as Coomassie staining.

In situ hybridization. In situ hybridization was conducted on $4 \%$ paraformaldehyde-postfixed adult rat brain sections as previously described (Fremeau and Popko, 1990).

$R N A$ probes. A 281 nucleotide fragment of Rel-N1 cDNA was excised from the TA vector (In Vitrogen) and subcloned into pGEM-3Zf(+) (Promega) and linearized. ${ }^{35} \mathrm{~S}$ (for in situ hybridization) or ${ }^{32} \mathrm{P}$ (for RNase protection assay) labeled single-stranded antisense RNA probes were synthesized using T7 RNA polymerase in the presence of ${ }^{35} \mathrm{~S}-\mathrm{UTP}$ (New England Nuclear) or ${ }^{32} \mathrm{P}$-UTP (ICN). A sense RNA probe was used as control for the in situ hybridization experiments. Unincorporated nucleotides were removed using G50 Sephadex (Pharmacia).

Ribonuclease protection assays. Total cellular RNA was prepared from various tissues of an adult male Sprague-Dawley rat according to methods described previously (Sambrook et al., 1989). Assays used $15 \mathrm{mg}$ of total RNA from each tissue source and ${ }^{32}$ P-labeled 281 nucleotide Rel-N1 probe as described by Zinn et al. (1983). Protected fragments were electrophoresed on a denaturing $5 \%$ polyacrylamide gel. The intcgrity of the RNA was ascertaincd by protection assay using "P-labcled antisense RNA transcribed from mouse $\beta 2$-microglobulin cDNA.

$R N A$ binding to $\mathrm{Hel}-\mathrm{Nl}$. For each binding reaction of $4 \mathrm{mg}$ of Staphylococcus A beads were washed three times in NT2 buffer $(150 \mathrm{~mm}$

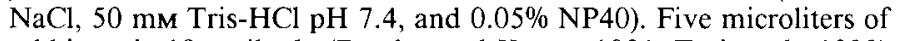
rabbit anti-g10 antibody (Bentley and Keene, 1991; Tsai et al., 1992) or $20 \mu \mathrm{l}$ of human serum was incubated with Staphylococcus A beads for $10 \mathrm{~min}$ on ice and washed three times with NT2 buffer (Query et al. 1989). Hel-N1 E. coli extract $(35 \mu$ ) was then added and incubated for $10 \mathrm{~min}$ on ice and washed three times with NT2 buffer. After the final wash, the protein complex was resuspended in $0.1 \mathrm{ml}$ of RNA binding buffer and equimolar amounts of labeled transcripts were added. Id cDNA was obtained from $\mathrm{H}$. Weintraub (Fred Hutchinson Cancer Center) and R. Benezra (Memorial Sloan Kettering Cancer Center). Dope control cDNA, a gift from M. Caron and R. Lcfkowitz (Duke University Medical Center), and $\mathrm{N}$-myc cDNA, a gift of J. Horowitz (Duke University Medical Center), were prepared as described (Levine et al., 1993). cDNA transcripts encoding Id mRNA were generated using the Bluescript vector and T3 polymerase after truncation at EcoRI, DraI, or PvuI based upon the published sequence (Benezra et al., 1990) and diagrammed in Figure $5 C$. Transcripts were prepared and bound as described previously (Levine et al., 1993). After a $5 \mathrm{~min}$ incubation at room temperature, the binding reaction was washed five times with NT2 buffer and resuspended in $0.1 \mathrm{ml}$ of NT2 buffer. An equivalent aliquot of the supernatant from the first wash was saved and treated identically as the bound pellet. Diethyl pyrocarbonate-treated water and $13 \mu \mathrm{l}$ of $5 \mathrm{M} \mathrm{NaCl}$ were added together with $1 \mu \mathrm{lof} 10 \mathrm{mg} / \mathrm{ml}$ tRNA. The reactions were phenol-chloroform-isoamyl alcohol extracted and ethanol precipitated. The pelleted RNA was separated on a $5 \%$ ureapolyacrylamide gel.

\section{Results}

Degenerate primers and PCR used to clone Rel-Nl and Hel-N1. We have used degenerate oligonucleotides and PCR to isolate novel mammalian RRM proteins in a manner similar to that of Kim and Baker (1993a) with Drosophila. We constructed PCR primers representing sense and antisense strands of the highly conserved RNP 1 consensus sequences of RRMs 1 and 2 (Hoffman et al., 1991; Kenan et al., 1991) of the Drosophila elav 


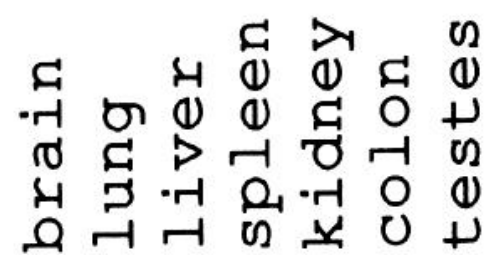

$300 \mathrm{bp}-$ 240bp -

Figure 2. Tissue-specific expression of Rel-N1 mRNA. Ribonuclease protection of hybrids between ${ }^{32} \mathrm{P}$ Rel-N1 antisense RNA and RNAs isolated from various tissue sources. A protected band was observed only with brain RNA, and on longer exposures a faint band was evident with testes RNA. Integrity of the RNA was ascertained by probing for $\beta 2$-microglobulin mRNA.

cDNA (Robinow et al., 1988). RNA from rat pup brain was reverse transcribed with random primers and used as a template for PCR as described in Materials and Methods. A PCR product, termed Rel-N1, representing cDNA between the octamers of RRM1 and RRM2 (Fig. 1A) was purified and sequenced. Rel$\mathrm{Nl}$ contained an ORF that was identical at the amino acid level to ELAV across this region. The cDNA of Rel-N1 was used to screen a human fetal brain library under high-stringency hybridization conditions and a 2.2 kilobase insert was isolated, sequenced, and found to contain an ORF representing 359 amino acids termed Hel-N1 (Fig. 1A). Stop codons were apparent in the $5^{\prime}$ region upstream of the AUG codon. Northern blot analysis of brain mRNA indicated that Hel-N1 is approximately $39 \mathrm{kDa}$ in size. The region of Rel-N1 used in these experiments was $93 \%$ homologous to Hel-N1 at the nucleic acid level. In vitro transcription and translation of the human Hel-N1 cDNA produced a protein of the predicted size, $37 \mathrm{kDa}$, which could be immunoprecipitated with anti-elav serum (gift of $\mathrm{K}$. White, Brandeis University; data not shown).

As shown in Figure 1, $A$ and $B$, Hel-N1 contained three RRMs, each with an RNP1 and RNP2 (boxed) consensus sequence. Comparison of these RRMs with those of Drosophila ELAV and $r b p 9$ (Kim and Baker, 1993b) showed strong similarities except for the variable loop 3 in RRM1 (Fig. $1 B$ ). At this locus, an additional 13 amino acids are present in ELAV but not in Hel-N1 or $r b p 9$. On the other hand, there were striking sequence differences at the amino termini of the proteins upstream of the RNA binding domains (Fig. $1 A$ ). In this region, Hel-Nl was much shorter (39 amino acids vs 149 for ELAV and 110 for Rbp9) and lacked the long homopolymeric stretches of glutamines and alanines seen in elav and arginines in $r b p 9$ (Fig. 1A). The original Rel-N1 PCR probe is represented by the sequence between RNP1 of RRM1 (residue L80 of Hel-N1) and RNP1 of RRM2 (residue F173 of Hel-N1) as shown in Figure $1 \mathrm{~A}$. These proteins contain similarities in the RRMs to a protein termed HuD (Szabo et al., 1991), but differ also at their amino termini and in the junction between RRMs 2 and 3. HuD is reported to be similar to Sex-lethal, a Drosophila RRM protein involved in the sex determination pathway (Bell et al., 1988; Baker, 1989). We conclude that ELAV, Hel-N1, and $r b p 9$ constitute members of a subfamily of the RRM superfamily of RNA-associated proteins (Kenan et al., 1991; Kim and Baker, 1993a) and, except for elav, designate them by species (H, R, etc.) and tissue $(\mathrm{N})$ of origin.

Rel-N1 is neuron specific. RNAs extracted from various rat tissues were analyzed by ribonuclease protection assays using antisense RNA for Rel-N1 as probe. A protected band was found only in RNA from rat brain (Fig. 2); however, longer exposures revealed a weak band using rat testes RNA (data not shown). To identify the specific neuroanatomic loci expressing Rel-N1 mRNA, 4\% paraformaldehyde-fixed rat brain sections were hybridized with ${ }^{35} \mathrm{~S}$-labeled antisense RNA derived from the PCR fragment of Rel-N1 (Fremeau and Popko, 1990). Data shown in Figure 3 revealed that Rel-N1 mRNA was heterogeneously distributed in adult rat brain. Prominent hybridization signals were observed throughout all layers of the cerebral cortex (Fig. $3 A, E)$. Within the hippocampus, Rel-N1 mRNA was heterogeneously distributed. High levels of expression were seen in the CA3-CA4 fields of Ammon's horn (Figs. $3 A, C, E ; 4)$. In contrast, only low levels of expression were observed in the CA1 field of Ammon's horn and the granule cells of the dentate gyrus (Figs. $3 A, D, E ; 4)$. Prominent hybridization signals were also observed throughout the thalamus and brainstem. Particularly intense hybridization signals were observed in the parafascicular and midline thalamic nuclei. Within the cerebellum, only a small percentage of labeled cells were observed in the granule cell layer and these cells showed morphological properties characteristic of Golgi cells (Fig. 3D,F). Only background labeling was observed over the molecular layer, the Purkinje cell layer (Fig. 3D), and the white matter tracts. Also, no significant labeling was observed over the choroid plexus, ependymal cells of the cerebral ventricles (Fig. $3 A, C-F$ ), or with control sections using a sense-strand probe (Fig. $3 B$ ).

In sum, these data indicate that Rel-N1 is heterogeneously expressed preferentially in certain neuronal populations throughout the brain. These findings are in contrast to in situ localization data reported for Drosophila elav in which this gene 

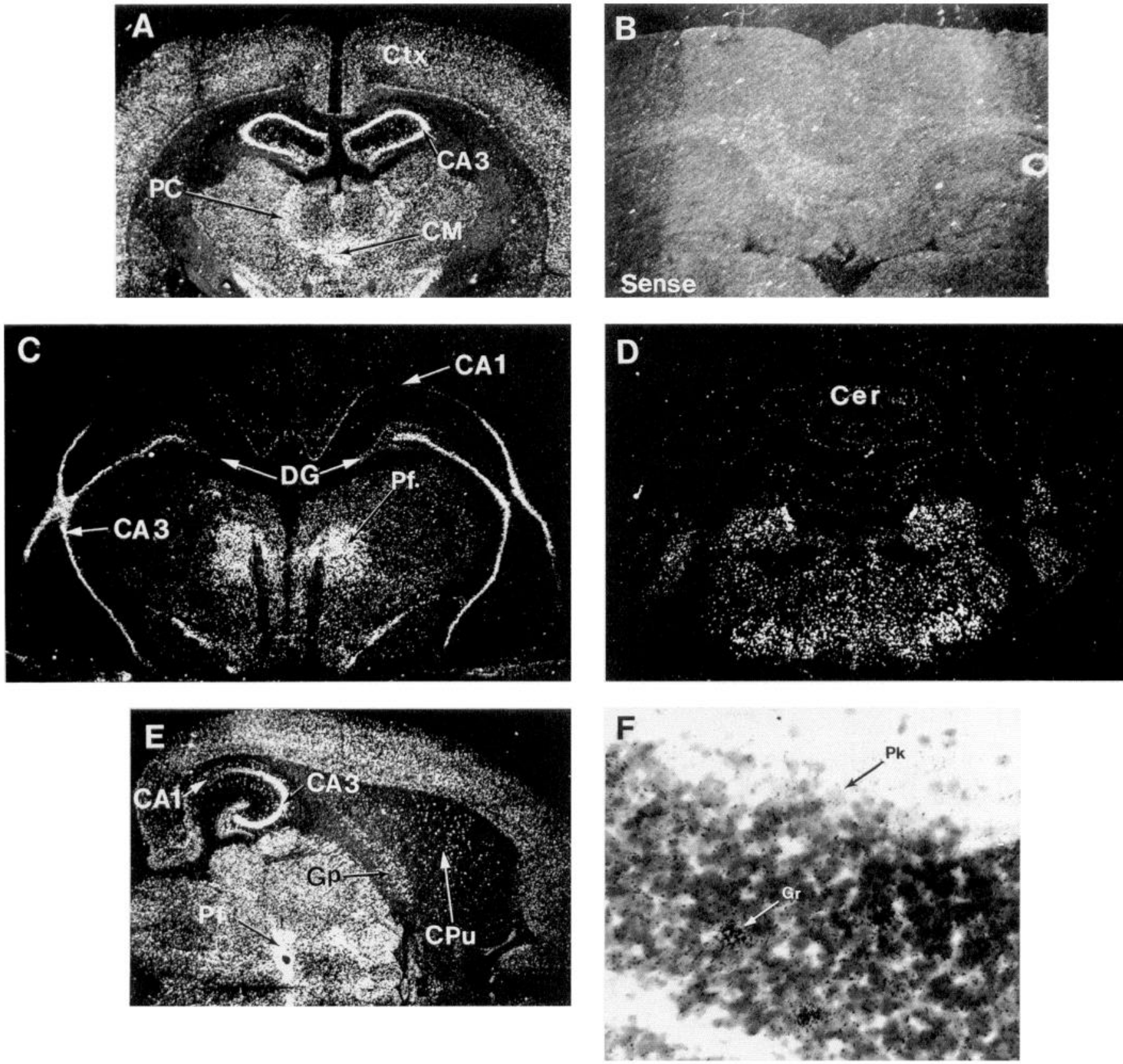

Figure 3. Localization of Rel-N1 RNA in the rat CNS using in situ hybridization. Coronal $(A, C, D, F)$ and horizontal $(E)$ sections of adult rat brain were hybridized with ${ }^{35}$ S-labeled antisense Rel-N1 cRNA. $B$, Coronal section adjacent to that in $A$ hybridized with a sense-strand control probe. $F$, Bright-field photomicrograph of the cerebellar cortex $(\mathrm{Cer})$ from $D$. Note that a small percentage of specifically labeled cells were observed in the granule cell layer of the cerebellum $(G r)$. In contrast, the Purkinje cells $(P k)$ were unlabeled. $C t x$, cerebral cortex; $C A 3$, field CA3 of Ammon's horn; $C M$, central median thalamic nucleus; $P C$, paracentral thalamic nucleus; $P f$., parafascicular nucleus of the thalamus; $C A 1$, field $C A 1$ of Ammon's horn; $D G$, granule cells of the dentate gyrus; $C P u$, caudate-putamen; $G p$, globus pallidus.

was found to be expressed in all neurons (Robinow and White, 1988).

Hel-NI Binds to the 3'end of Id mRNA. Despite the presence of three identifiable RRMs, target RNA molecules have not yet been identified for ELAV or $r b p 9$. Our search for potential ligands for Hel-N1 was directed by results of in vitro randomized RNA selection experiments using Hel-N1 (Levine et al., 1993; Tsai et al., 1991), which showed preferences for binding to short uridylate-rich regions in RNA. Based on the known role of elav in Drosophila, we examined sequences of RNAs involved in neural development. Id mRNAs were found to contain short stretches of uridylates in the 3' UTRs (Table 1) that are similar to those shown to bind Hel-N1 in vitro (Levine et al., 1993). To test for binding to Id mRNA, an in vitro transcript of Id mRNA along with Dopc and N-myc control mRNAs were each incubated with recombinant epitope-tagged Hel-Nl using standard RNA binding methods (Query et al., 1989; Bentley and Keene, 1991). Following immunoprecipitation with the epitopespecific antibody (anti-g10), bound products were analyzed on a denaturing acrylamide gel. As shown in Figure $5 A$, lane 1, Id mRNA terminating at a DraI truncation site in the middle of the $3^{\prime}$ UTR (Fig. $5 C$ ) was able to bind, while the control mRNAs 

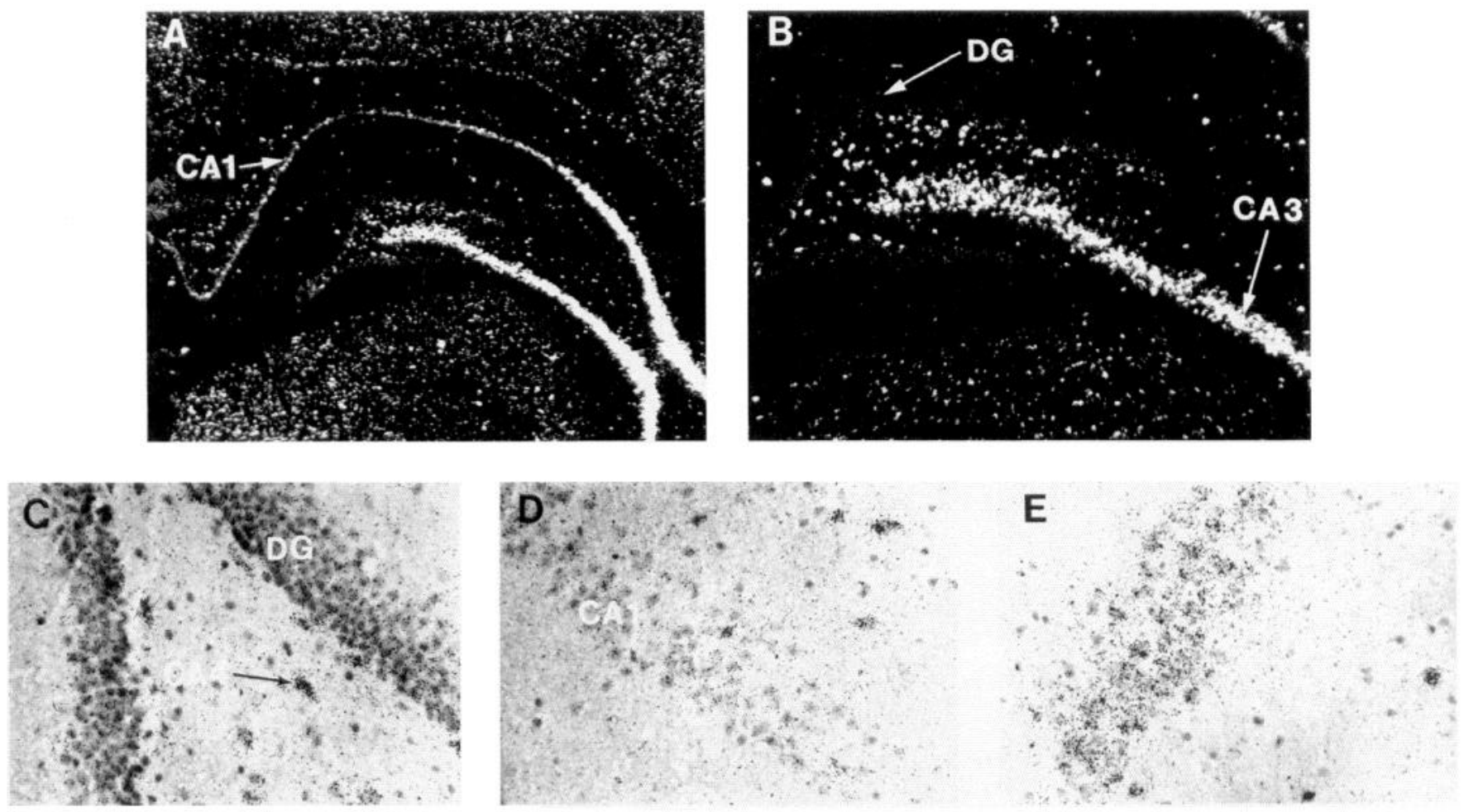

Figure 4. Cellular specificity of expression of Rel-N1 mRNA in adult rat hippocampus. Dark-field photographs of emulsion autoradiography revealed that silver grains were localized primarily over pyramidal neurons in the CA3-CA4 fields of Ammon's horn $(A, B)$. In contrast, only background labeling was observed over pyramidal neurons of the CAl field and granule neurons of the dentate gyrus $(D G)$. $C$, Bright-field photomicrograph demonstrating background labeling over the granule neurons of the dentate gyrus. Note the labeled pyramidal neurons in the CA4 field (arrow). D. Bright-field photomicrograph demonstrating background labeling over the pyramidal neurons of the CAI field of Ammon's horn. However, labeled interneurons were observed scattered throughout the neuropil layers of the hippocampus. $E$, Bright-field photomicrograph demonstrating intense labeling over the pyramidal neurons of the CA3 field of Ammon's horn.

did not bind to Hel-N1. Input RNAs were routinely examined by electrophoresis of supernatants from the immunoprecipitation reactions and found to be intact (Fig. 5A, lanes 4-6). Both control RNAs included coding and noncoding sequences as described previously (Levine et al., 1993). Other control transcripts including hYl, 70K, and U1 RNA, as well as several unrelated in vitro transcripts did not bind to Hel-N1 (Levine et al., 1993; data not shown).
To determine whether sequences in the coding region of Id mRNA were required for Hel-N1 binding, three constructs were used to generate in vitro transcripts as shown in Figure $5 C$. Immunoprecipitation was carried out using both anti-g10 antibody and an anti-Hu autoimmune serum (Dalmau et al., 1990) which was shown previously to recognize Hel-N1 during RNA binding (Levine et al., 1993). Binding to Id mRNA was abolished when the $3^{\prime}$ UTR and 15 nucleotides from of the carboxy-

Table 1. Short stretches of uridylate-rich sequences found in the $3^{\prime}$ UTRs of cDNAs encoding Id homologs of the helix-loop-helix proteins

$\begin{array}{llllll}\text { Mouse Id } & \text { Human } & \text { Mouse } & & & \\ \text { Id2 } & \text { HLH-462 } & \text { Drosophila extramacrochaetae } & \text { GUUUA } \\ \text { AUUUUA } & \text { AUUUC } & \text { AUUUUG } & \text { AUUUA } & \text { AUUUC } & \text { GUUUA } \\ \text { AUUUC } & \text { AUUUC } & \text { AUUUUUG } & \text { AUUUA } & \text { AUUUC } & \text { GUUUA } \\ \text { CUUUA } & \text { AUUUUC } & \text { CUUUUUA } & \text { AUUUA } & \text { AUUUC } & \text { GUUUA } \\ \text { CUUUC } & \text { CUUUUA } & \text { CUUUUUA } & \text { AUUUA } & \text { AUUUUC } & \text { GUUUC } \\ \text { CUUUG } & \text { CUUUUA } & \text { CUUUUC } & \text { AUUUUA } & \text { AUUUUC } & \text { GUUUUC } \\ \text { GUUUUA } & \text { CUUUG } & \text { CUUUC } & \text { AUUUUA } & \text { CUUUA } & \text { GUUUUC } \\ \text { GUUUUA } & \text { CUUUU } & \text { CUUUUG } & \text { AUUUUA } & \text { CUUUA } & \text { GUUUUC } \\ \text { GUUUC } & & \text { GUUUC } & \text { AUUUC } & \text { CUUUUC } & \text { GUUUUG } \\ \text { GUUUG } & & & \text { AUUUC } & \text { CUUUG } & \text { GUUUUG }\end{array}$

This table gives short stretches of uridylate-rich sequences found in the $3^{\prime}$ UTRs of cDNAs encoding helix-loop-helix proteins, including Id mRNA (Benezra et al., 1990), human Id2 mRNA (Biggs et al., 1992), mouse HLH462 mRNA (Christy et al., 1991) and Drosophila extramacrochaetae mRNA (Ellis et al., 1990; Garrell and Modolell, 1990). Similar sequences were found previously to be selected from random pools of RNA by binding to recombinant Hel-N1 protein (Levine et al., 1993). 
A

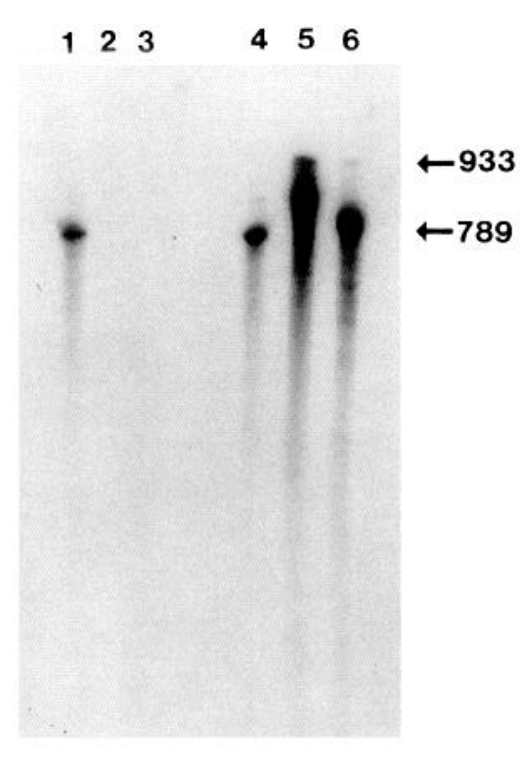

Transcripts of Id mRNA

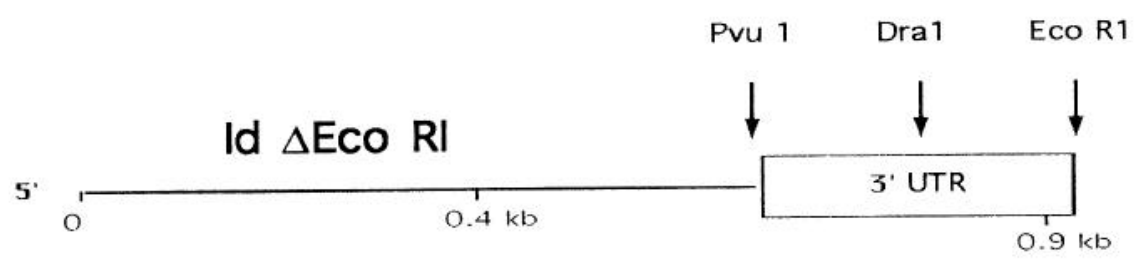

Id $\Delta$ Dra I

$\mathbf{s}^{\prime}$

\section{Id $\Delta$ Pvu I}

$\mathbf{5}^{\prime}$

terminal coding region were deleted by cleavage with PvuI (Fig. $5 B$, lanes 1,4$)$. This transcript was shown to remain intact when supernatants of the binding reaction were examined (data not shown). Binding to Id mRNA was retained, however, when either the DraI (Fig. $5 B$, lanes 2, 5) or the EcoRI truncated transcript (Fig. $5 B$, lanes 3,6 ) were bound. The EcoRI transcript represented the entire $3^{\prime}$ UTR sequence, but was consistently observed as a smeared band by acrylamide gel electrophoresis. PEM autoimmune serum was as effective as anti-g10 serum in the immunoprecipitation/RNA-binding experiments, indicating that anti-HuD autoantibodies can bind to Hel-N1 without interfering with its binding to the Id mRNA. These data indicate that the sequence extending from the DraI site to the PvuI site and perhaps other sequences in the $3^{\prime}$ UTR are essential for binding to Hel-N1. Table 2 confirms this conclusion by showing radioactive counts in a typical binding experiment in comparison with the c-myc 3' UTR (Levine et al., 1993). As expected, the Id $\Delta$ PvuI transcript was not able to bind to Hel-N1. Whether Hel-N1 directly binds to a primary sequence in the $3^{\prime}$ UTR of Id mRNA or recognizes a secondary structure in that region is not known.

It is interesting to note that the $3^{\prime}$ UTR of Id and other helixloop-helix proteins (Table 1) contain short stretches of uridylaterich sequences (Benezra et al., 1990; Christy et al., 1991) similar to those identified previously as important for Hel-N1 binding (Levine et al., 1993). The function of these sequences in the $3^{\prime}$ UTR is not known but they may play a role in mRNA stability, localization, or translatability. Increasing evidence suggests an important regulatory role for various mRNA 3' UTRs (Rastinejad and Blau, 1993). Equally interesting was the finding of 
Table 2. Relative binding of Hel-N1 to Id transcripts in comparison with transcripts containing the e-myc 3 UTR

\begin{tabular}{lcl} 
RNA transcript & cpm Bound & Ratio \\
\hline $\begin{array}{l}\text { c-myc 3' UTR } \\
\text { Id coding plus 3' UTR } \\
\text { (Id } \Delta \text { EcoRI) }\end{array}$ & 45,600 & 283 \\
$\begin{array}{l}\text { Id coding only } \\
\text { (Id } \Delta \text { PvuI) }\end{array}$ & 21,544 & 98 \\
\end{tabular}

Data show relative binding of Hel-N1 to Id transcripts in comparison with c-myc 3' UTR (Levine et al., 1993). cpm, Total counts per minute bound in RNA binding assay using glo epitope tag; ratio, the relative ratio of radioactivity bound per number of uridylate residues in cach transeript.

extensive sequences of this type in the 3' UTR of the Drosophila protein from the extramacrochaetae (emc) locus (Table 1; Ellis et al., 1990; Garrell and Modolell, 1990). The EMC protein is a member of the helix-loop-helix group and is highly similar to Id. It is not known whether a genetic relationship exists between emc and elav, or whether ELAV can bind to the EMC 3 UTR.

\section{Discussion}

We report the cloning and characterization of Hel- $\mathrm{N} 1$ and Rel$\mathrm{N} 1$, new mammalian homologs of Drosophila ELAV, and show that Hel-N1 can bind in vitro to Id mRNA that encodes a helixloop-helix transcriptional repressor. These findings are intriguing in light of the phenotype of the elav mutation, which indicates an csscntial rolc in neural growth and development (Campos ct al., 1985; Jiminez and Compos-Ortega, 1987). The sequence divergence among EIAV, Rbp9, and Hel-NI at the amino termini and in loop 3 of RRM1 indicates they are each distinct (Fig. 1). Genetic experiments performed with elav, however, suggest that the amino terminus is not essential for function (Yao and White, 1991). This observation is based on a genetic rescue study that involved the lethal mutation $e$ la $v^{x^{-5}}$ (which lacks both the elav ORF and the promoter). It was determined that an ORF encoding an ELAV protein with a 40-amino acid delction within the glutamine/alanine-rich region could rescue the elaves mutant from lethality (Yao and White, 1991). The role of these amino-terminal sequences in RNA metabolism is yet to be determined, but expression of the RRMs of ELAV alone was sufficient for normal function.

Loop 3 of the RRM structure is highly variable in sequence (Kenan et al., 1991) and was shown to contain a determinant of specificity for recognition of $\mathrm{U} 1$ and $\mathrm{U} 2$ small nuclear RNAs by the U1A and U2B" proteins, respectively (Scherly et al., 1990; Bentley and Keene, 1991). Loop 3 is highly conserved in RRM1 of ELAV, Rbp9 and Hel-N1 (Fig. 1B), suggesting that it may recognize the same RNA sequence in each case. Since the RNA binding specificity of each RRM is not known, however, the significance of an additional 13 amino acids in loop 3 of the ELAV protein remains unknown.

In general, it is evident that sequences in the RRMs of all three proteins are highly conserved (Fig. 1), suggesting they are truly homologous. It is reasonable to predict that they have similar RNA binding specificities. However, sequences outside the RRMs may be found to function as determinants of RNA binding specificity as shown previously for other RRM proteins (Query et al., 1989; Bentley and Keene, 1991). Thus, given the diversity of sequences outside of known RRMs that can influence RNA recognition (Kenan et al., 1991), it will be necessary to determine the RNA binding targets for each of these ELAVlike proteins regardless of their apparent homologies.

Rel-NI is heterogeneously distributed within the CNS. In situ hybridization revealed that the mRNA for Rel-NI was localized in subpopulations of neurons in the CNS. In particular, high levels of expression were observed in the pyramidal neurons of the CA3-CA4 ficlds of Ammon's horn, as well as neurons in various thalamic and brainstem nuclei (Figs. 3,4). We cannot exclude the possibility that there are very low levels of expression of Rel-N 1 in glial cells, below the level of sensitivity of our in situ hybridization technique. The more limited distribution of Rel-N1 expression is in contrast to that of elav, which appears to be ubiquitous in neurons of the Drosophila nervous system The significance of this difference in distribution is unclear, although the Drosophila probes were derived from full-length clav cDNA (Robinow and White, 1988) whereas the Rel-Nl probe was directed to a region spanning RRMs 1 and 2 . Therefore, these hybridization studies may have detected different subsets of ELAV-like family members.

Implications of Ilel-NI binding to Id $m R N A$. Numerous genes expressed in mammalian neural tissue are highly conserved as Drosophila homologs including MASH 1, MASH 2 (Johnson et al., 1990), Id (Benezra et al., 1990), GAP-43 (Jacobson et al., 1986), and Hox-2 and Hox-5 (Featherstone et al., 1988; Graham et al., 1989; Kessel and Gruss, 1990). Similar patterns of expression among these genes indicate that certain genetic programs of neural growth may have been conserved through evolution. Our demonstration that Hel-N1, another highly conserved neuronal protein, binds to mRNA of the transcriptional regulator Id raises intriguing possibilities as to the role of elav and its subfamily in neural growth and maintenance. Recently, Duncan et al. (1992) demonstrated an abundance of Id mRNA expression early in the development of the mouse nervous system, followed by a rapid decline as neural precursors differentiated into neurons. These findings suggest that Id is present only in undiflerentiated mitotic cells and that it may have a negative regulatory role in differentiation of neurons. Moreover, Id2, which has $90 \%$ homology to $\mathrm{Id}$, is also expressed at high levels in early fetal brain tissue but not in mature brain (Biggs et al., 1992). The expression of Id 2 is also downregulated in a neuroblastoma cell line following induction of ganglionic differentiation with retinoic acid. In addition, the Drosophila homolog of Id, extramacrochaetae (emc), plays a regulatory role in the development of sensory organs (Botas et al., 1982; Moscoso del Prado and Garcia-Bellido, 1984; Ellis et al., 1990; Garrell and Modolell, 1990; Van Doren et al., 1991). However, a functional relationship between emc and elav has not been documented.

Based on the observations reported here, the potential involvement of Hel-N1 in Id mRNA metabolism is consistent with it playing an important role in neural development. For example, the rapid decline in Id mRNA following differentiation of mammalian neuroblasts (Duncan, 1992) coincides temporally with the initial appearance of elav transcripts in Drosophila neural development (Robinow and White, 1988). Thus, an effect on Id expression through modulation of its mRNA could represent a fundamental aspect of early neural differentiation. RNAbinding factors have been implicated in control of gene expression through such mechanisms as mRNA stability (Shaw and Kamen, 1986; Richter, 1988; Schuler and Cole, 1988; Malter, 1989; Mullner et al., 1989; Vakalopoulou et al., 1991) or mRNA translation (Aziz and Munro, 1987). However, such interactions 
have not been documented to occur in the CNS. It will be important to determine whether Hel-N1 or other members of the elav subfamily participate directly in the regulation of expression of Id and other helix-loop-helix proteins.

Binding of Hel-N1 to the 3' UTR of Id mRNA has particular relevance because of recent work demonstrating the importance of 3 ' UTRs in growth and differentiation. Through genetic complementation using a differentiation-defective myoblast mutant, Rastinejad and Blau (1993) demonstrated that the 3' UTRs of certain muscle genes can play a regulatory role in cell division and differentiation. Whether interactions between $\mathrm{Hel}-\mathrm{N} 1$ and the 3' UTR of Id mRNA can affect neural functions is not yet known, however. This hypothesis is consistent with the genetic phenotype and neuronal characteristics associated with elav in Drosophila. Findings reported here and interactions demonstrated previously between Hel-N1 and sequences in the $3^{\prime}$ UTRs of growth factor mRNAs (Levine et al., 1993) are consistent with this hypothesis because it is necessary that cell proliferation cease prior to entry into a program of differentiation (Chamberlain et al., 1985). Whether Hel-N1 represents a neural-specific trans-acting RNA-binding protein that affects these developmental processes is yet to be determined.

\section{References}

Adam SA, Nakagawa TY, Swanson MS, Woodruff T (1986) mRNA polyadenylate-binding protein: gene isolation and sequencing and identification of a ribonucleoprotein consensus sequence. Mol Cell Biol 6:2932-2943.

Aziz N, Munro HN (1987) Iron regulates ferritin mRNA translation through a segment of its $5^{\prime}$ untranslated region. Proc Natl Acad Sci USA 84:8478-8482.

Baker BS (1989) Sex in flies: the splice of life. Nature 340:521-524.

Bell L, Maine EM, Schedl P, Cline TW (1988) Sex-lethal, a Drosophila sex determination switch gene, exhibits sex-specific RNA splicing and sequence similarity to RNA binding proteins. Cell 55:1037-1046.

Benezra R, Davis RL, Lockshon D, Turner DL, Weintraub H (1990) The protein Id: a negative regulator of helix-loop-helix DNA binding proteins. Cell 61:49-59.

Bentley RC, Keene JD (1991) Recognition of U1 and U2 small nuclear RNAs can be altered by a 5 -amino-acid segment in the U2 small nuclear ribonucleoprotein particle (snRNP) and through interactions with U2 snRNP-A' protein. Mol Cell Biol 11:1829-1839.

Biggs J, Murphy EV, Israel MA (1992) A human Id-like helix-loophelix protein expressed during early development. Proc Natl Acad Sci USA 89:1512-1517.

Botas J, Moscoso del Prado J, Garcia-Bellido A (1982) Gene-dose titration analysis in the search of trans-regulatory genes in Drosophila. EMBO J 1:307-310.

Campos AR, Grossman D, White K (1985) Mutant alleles at the locus elav in Drosophila melanogaster lead to nervous system defects. A developmental-genetic analysis. J Neurogenet 2:197-218.

Chamberlain JS, Jaynes JB, Hauschka SD (1985) Regulation of creatine kinase induction in differentiating mouse myoblasts. Mol Cell Biol 5:484-492.

Christy BA, Sanders LK, Lau LF, Copeland NG, Jenkins NA, Nathans D (1991) An Id-related helix-loop-helix protein encoded by a growth factor-inducible gene. Proc Natl Acad Sci USA 88:1815-1819.

Dalmau J, Furneaux HM, Gralla RJ, Kris MG, Posner JB (1990) Detection of the anti-Hu antibody in the serum of patients with small cell lung cancer-a quantitative Western blot analysis. Ann Neurol 27:544-552.

Dreyfuss G, Swanson MS, Pinol-Roma S (1988) Heterogeneous nuclear ribonucleoprotein particles and the pathway of mRNA. Trends Biochem Sci 13:86-91.

Duncan M, DiCicco-Bloom EM, Xiang X, Benezra R, Chada K (1992) The gene for the helix-loop-helix protein, Id, is specifically expressed in neural precursors. Dev Biol 154:1-10.

Ellis HM, Spann DR, Posakony JW (1990) extramacrochaetae, a negative regulator of sensory organ development in Drosophila, defines a new class of helix-loop-helix proteins. Cell 61:27-38.
Featherstone MS, Baron A, Gaunt SJ, Mattei M, Duboule D (1988) Hox-5.1 defines a homeobox-containing gene locus on mouse chromosome 2. Proc Natl Acad Sci USA 85:4760-4765.

Feinberg A, Vogelstein B (1983) A technique for radiolabeling DNA restriction endonuclease fragments to high specific activity. Anal Biochem 132:6-13

Fremeau RT, Popko B (1990) In situ analysis of myelin basic protein gene expression in myelin-deficient oligodendrocytes: antisense hnRNA and readthrough transcription. EMBO J 9:3533-3538.

Garrell J, Modolell J (1990) The Drosophila extramacrochaetae locus, an antagonist of proneural genes that, like these genes, encodes a helixloop-helix protein. Cell 61:39-48.

Graham A, Papalopulu N, Krumlauf R (1989) The murine and Drosophila homeobox gene complexes have common features of organization and expression. Cell 57:367-378.

Hoffman DW, Query CC, Golden BL, White SW, Keene JD (1991) Structural analysis of the RNA binding domain of the U1 snRNP-A protein using nuclear magnetic resonance spectroscopy reveals similarity to ribosomal proteins. Proc Natl Acad Sci USA 88:2495-2499.

Jacobson RD, Virag I, Skene JHP (1986) A protein associated with axon growth, GAP-43, is widely distributed and developmentally regulated in rat CNS. J Neurosci 6:1843-1855.

Jiminez F, Campos-Ortega JA (1987) Genes in subdivision 1B of the Drosophila melanogaster X-chromosome and their influence on neural development. J Neurogenet 4:179-200.

Johnson JE, Birren SJ, Anderson DJ (1990) Two rat homologues of Drosophila achaete-scute specifically expressed in neuronal precursors. Nature 346:858-860.

Kenan DJ, Query CC, Keene JD (1991) RNA recognition: towards identifying determinants of specificity. Trends Biochem Sci 16:214220.

Kessel M, Gruss P (1990) Murine developmental control genes. Science 249:374-379.

Kim YJ, Baker BS (1993a) Isolation of RRM-type RNA-binding protein genes and the analysis of their relatedness by using a numerical approach. Mol Cell Biol 13:174-183.

Kim YJ, Baker BS (1993b) The Drosophila gene rbp9 encodes a protein that is a member of a conserved group of putative RNA binding proteins that are nervous system-specific in both flies and humans. $\mathbf{J}$ Neurosci 13:1045-1056.

Levine TD, Gao F-B, King PII, Andrews LG, Keene JD (1993) Ifel$\mathrm{N} 1$ : an autoimmune RNA-binding protein with specificity for $3^{\prime}$ uridylate-rich untranslated regions of growth factor mRNAs. Mol Cell Biol 13:3494-3504.

Malter JS (1989) Identification of an AUUUA-specific messenger RNA binding protein. Science 246:664-666.

Moscoso del Prado J, Garcia-Bellido A (1984) Genetic regulation of the Achaete-scute complex of Drosophila melanogaster. Rouxs Arch Dev Biol 193:242-245,

Mullner EW, Neupert B, Kuhn LC (1989) A specific mRNA binding factor regulates the iron-dependent stability of cytoplasmic transferrin receptor mRNA. Cell 58:373-382.

Query CC, Bentley RC, Keene JD (1989) A common RNA recognition motif identified within a defined U1 RNA binding domain of the 70K U1 snRNP protein. Cell 57:89-101.

Rastinejad F, Blau HM (1993) Genetic complementation reveals a novel regulatory role of $3^{\prime}$ untranslated regions in growth and differentiation. Cell 72:903-917.

Richter JD (1988) Information relay from RNA to protein: the mRNP connection. Trends Biochem Sci 13:483-486.

Robinow S, White K (1988) The locus elav of Drosophila melanogaster is expressed in neurons at all developmental stages. Dev Biol 126: 294-303.

Robinow S, Campos A, Yao K, White K (1988) The elav gene product of Drosophila, required in neurons, has three RNP consensus motifs. Science 242:1570-1572.

Rosenberg AH, Lade BN, Chui DS, Dunn JJ, Studier FW (1987) Vectors used for selective expression of cloned DNAs by $T 7$ polymerase. Gene 56:125-135.

Sambrook J, Fritsch EF, Maniatis T (1989) Molecular cloning: a laboratory manual, $2 \mathrm{~d}$ ed. Cold Spring Harbor, NY: Cold Spring Harbor Laboratory.

Sanger F, Nicklen S, Coulson AR (1977) DNA sequencing with chain terminating inhibitors. Proc Natl Acad Sci USA 74:5463-5467.

Scherly D, Dathan NA, Boelens W, van Venrooij WJ, Mattaj IW (1990) 
The U2B" RNA motif as a site of protein-protein interaction. EMBO J 9:3675-3681.

Schuler GD, Cole MD (1988) GM-CSF and oncogene mRNA stabilities are independently regulated in trans in a mouse monocytic tumor. Cell 55:1155-1122.

Shaw G, Kamen R (1986) A conserved AU sequence from the $3^{\prime}$ untranslated region of GM-CSF mRNA mediates selective mRNA degradation. Cell 46:659-667.

Szabo A, Dalmau J, Manley G, Rosenfeld M, Wong E, Henson J, Posner JR, Furneaux HM (1991) $\mathrm{HuD}$ a paraneoplastic encephalomyelitis antigen contains RNA binding domains and is homologous to $E L A V$ and sex-lethal. Cell 67:325-333.

Tabor S, Richardson CC (1987) DNA sequence analysis with a modificd bacteriophage T7 DNA polymerase. Proc Natl Acad Sci USA $84: 4767-4771$.

Tsai DE, Harper DS, Keene JD (1991) U1-snRNP A protein selects a ten nucleotide consensus sequence from a degenerate RNA pool presented in various structural contexts. Nucleic Acids Res 19:49314936.
Tsai DE, Kenan DJ, Keene JD (1992) In vitro selection of an RNA epitope immunologically crossreactive with a peptide. Proc Natl Acad Sci USA 89:8864-8868.

Vakalopoulou E, Schaak J, Shenk T (1991) A 32 kilodalton protein binds to $\mathrm{AU}$-rich domains in the 3 untranslated regions of rapidly degraded mRNAs. Mol Cell Biol 1 1:3355-3364.

Van Doren M, Ellis HM, Posakony JW (1991) The Drosophila extramacrochaetae protein antagonizes sequence-specific DNA binding by daughterless/achaete-scute protein complexes. Development 113:245255

Yao K, White K (1991) Organizational analysis of elav gene and functional analysis of ELAV protein of Drosophila melanogaster and Drosophila virilis. Mol Cell Biol 1 1:2994-3000.

Zinn K, Dimaio T, Maniatis T (1983) Identification of two distinct regulatory regions adjacent to the human $\beta$-interferon gene. Cell 34 : $865-879$. 